\title{
POST INFECTION AND POST VACCINATION IMMUNE RESPONSE TO EQUINE INFLUENZA A VIRUS AND EQUINE HERPES VIRUS 1 AND 4 IN HORSES
}

\author{
D. GUNDASHEVA
}

\author{
Department of General and Clinical Pathology, Faculty of Veterinary \\ Medicine, Trakia University, 6000 Stara Zagora, Bulgaria
}

\begin{abstract}
Summary
Gundasheva, D., 2018. Post infection and post vaccination immune response to equine influenza A virus and equine herpes virus 1 and 4 in horses. Bulg. J. Vet. Med., 21, No 4, 381-390.

The overview summarised data from contemporary studies on immune response against two of the most contagious respiratory diseases in horses - influenza and herpes viral infections. It goes over the generation of immune response in this animal species after vaccination against the viral antigens. The knowledge of mechanisms of immune system response to the infections and respective vaccinations are essential for equine health, particularly with regard to full recovery of their athletic performance.
\end{abstract}

Key words: EHV-1 and 4, horses, immune response, influenza A (H7N7 and H3N8), vaccination

\section{INTRODUCTION}

The equine influenza virus and the equine herpesvirus infections of horse populations are of serious health and economic concerns. Influenza A virus causes a respiratory tract infection which is highly contagious especially for young horses at high population density and for competing equine athletes. The short-term immunity and antigenic variation of viral strains are responsible for frequent re-infections. Equine herpesvirus type 1 and 4 (EHV-1; EHV-4) are also acknowledged as respiratory pathogens inducing disease with similar signs. Apart rhinopneumonitis, EHV-1 could cause neurological disorders, abor- tions in pregnant mares and severe ocular pathology. The primary means of control of these infections are vaccination programmes, early recognition and quarantine. Despite the large-scale implementation of vaccination, the associated defense mechanisms are poorly studied except for their ability to produce virus-neutralisation antibodies. Therefore, the aim of the review was to present the most recent information concerning the immune response to influenza and herpes viral infections, and after vaccination against these viral diseases in the horse. 


\section{POST INFECTION IMMUNE RESPONSE TO EQUINE INFLUENZA VIRUS AND EQUINE HERPESVIRUS}

Influenza A (H7N7 and H3N8) viral infection causes respiratory illness in horses which is broadly spread, with high morbidity rates and substantial economic losses. In young horses, this highly contagious disease is manifested with fever, depression, anorexia, rapid exhaustion, painful dry cough, nasal discharge, often a secondary bacterial co-infection (mainly with $\beta$-haemolytic streptococci) is present (Barquero et al., 2007; Tsachev, 2007; Diaz-Mendez et al., 2010). The highest prevalence of the disease was observed in 2- to 3-year-old horses (Landolt et al., 2007).

Daly et al. (2004) reported that immunity raised after application of inactivated influenza vaccines was dependent on the high levels of circulating antibodies against viral haemagglutinins, so when such antibodies were not present, vaccinated horses were sensitive to infection. On the contrary, natural infection with influenza A/equine/Newmarket/79 (H3N8) virus induces long-term immunity to reinfection with homologous strains, even during absence of antibodies at the time of re-infection. According to the researchers, cell-mediated immune response is also involved in systemic defense against this infection, but it is less thoroughly studied. In men, antibody response is reported to reduce viral load and to restrict reinfection, and the role of cellular immune mechanisms was suggested to be more important for elimination of the virus during the period of recovery (McMichael et al., 1983). At present, specific lymphoproliferative response to influenza $\mathrm{A}$ virus and INF- $\gamma$ gene expression could be the best criterion for virus-specific cellular immune response in horses (Landolt et al.,
2007). In ponies, experimentally infected with influenza virus (H3N8), genetically restricted antigen-specific response performed by cytotoxic $\mathrm{T}$ lymphocytes (CTL) has been detected. It is assumed that the activation of CTL was preceded by endogenous antigen processing followed by peptide presentation through MHC class I molecules (Daly et al., 2004). The application of inactivated viral vaccinal antigens by the same researchers did not result in stimulation of a potent CTL response, because these antigens have underwent exogenous processing and presentation by MHC class II.

Changes in nonspecific immune defense manifested with leukocytosis with left shift, neutrophilia, lymphocytopaenia, monocytosis, enhanced erythrocyte sedimentation rate are reported in donkeys and mules with influenza by Tsachev et al. (1994).

In horses, evidence about local induction of specific IgGa and $\operatorname{IgGb}$ at the surface of respiratory mucosa has been provided, as well as indirect data that virusspecific nasal IgGb antibody response could contribute to reduction of nasal shedding of influenza virus (Landolt et al., 2007). According to the authors, circulating IgGa and IgGb are assumed to be primary protective IgG-isotype response to influenza virus, while the $\operatorname{IgG}(\mathrm{T})$ response was not associated with protection.

Equine herpesviruses of type 1 and type 4 which are closely related genetically and antigenically, induce a respiratory infection - rhinopneumonitis (Anonymous, 2008; Bresgen et al., 2012). It is more prevalent among young horses between weaning and 2-3 years of age (Powell, 1991; Walter, 2013). Airways infection in foals caused by hypervirulent EHV-1 strains could be accompanied by severe uveitis and/or chorioretinitis (Slater 
et al., 1992). Furthermore, EHV-1 could result in myeloencephalopathy, and in mares in late pregnancy - in abortions or mortality of neonatal foals (Bresgen et al., 2012; Goodman et al., 2012; Walter, 2013). Central nervous system disorders caused by this infection are clinically manifested with abnormal gait (ataxia), partial sensory disturbances, paralysis and death (Mohd-Azmi, 2002, Pusterla et al., 2009). EHV-1 induced neurological pathology is mainly restricted to the vascular epithelium of arteries supplying the central nervous system, although the trigeminal ganglion is also involved and the resulting inflammatory response leads to myeloencephalitis. Elderly horses, mares and febrile horses are at higher risk for developing severe neurological illness (Goehring et al., 2006).

In pregnant mares, EHV-1 infected placenta leads to abortions, and uterine infections could result in severe pulmonary complications in foals born alive (Perkins et al., 1995). After infection with EHV-1, susceptible foals remain lifelong carriers of the virus (Edington et al., 1986). CD5+ CD8+ T lymphocytes are the target cells maintaining EHV-1 latency (Tsachev, 2007; Paillot et al., 2008). Allen et al. (2006) detected a latent infection in submandibular lymph nodes of mares, experimentally infected with EHV-1. Different stressors (castration, transportation, weaning) as well as treatment with corticosteroids could reactivate the latent virus and cause virus replication and shedding (Mohd-Azmi, 2002).

Anti-EHV-1 immune response, either post-infection or post-vaccination, is short and incomplete, due to immunomodulatory properties of the virus (Hussey et al., 2011). These properties are manifested through an array of viral strategies, including interference and modulation of the
NK lysis, changed response of cytokines effecting B- and T-cellular response, loss of efficient antigen presentation and haemoattraction of antigen-presenting cells, antibody-dependent cytotoxicity and cytotoxic T-cellular lymphocytic response (Van der Meulen et al., 2006). The duration of the protection against re-infection provided by humoral immune response to EHV lasts from 3 to 6 months (Slater, 2007).

Paillot et al. (2008) reported changes in innate immunity occurring several days after infection with EHV-1, comprising increased proportion of neutrophils and lower percentage of monocytes and lymphocytes in lungs, presence of type 1 interferons $(\mathrm{INF} \alpha / \beta)$ in nasal secretions and blood serum (first and second post infection weeks), as well as altered cellmediated immunity with increase in the number of bronchoalveolar CD8+ T lymphocytes and their cytotoxic activity against EHV-1 infected cells (third post infection week).

Humoral immune response to EHV-1 challenge in horses occurs at least 2 weeks after infection and consists in formation of complement-fixing antibodies, virusneutralising antibodies, especially from IgGa, IgGb, IgGc, IgG(T) and IgM serotypes, as well as a dominating local mucosal specific $\operatorname{IgA}$ with virus-neutralising activity (Breathnach et al., 2001; Paillot et al., 2008). These antibodies, however, are not effective against intracellular EHV-1. Cell-mediated immune response, evaluated through alternative measurement of IFN- $\gamma$ (synthesised by Th1 lymphocytes), augments the presentation of viral peptides by antigen-presenting cells and the involvement of CTL destroying infected cells. The percentage of EHV-1 specific cells synthesising IFN $\gamma+$ increases during the second week post infection in an ex- 
perimental pony model and deceases 3-4 weeks later (Paillot et al., 2007), nonetheless, they could persist one year after the challenge (Allen et al., 1995).

Kidd et al. (2003) investigated the adaptive immune response and protection in horses infected with EHV-1. They found out that virus-neutralising antibodies were important for reduction of nasal virus shedding while CTL exhibited the strongest protective effect against clinical disease, viraemia and virus shedding. The duration of immunity against EHV-1 was from 3 to 6 months (Kydd et al., 2006). Hussey et al. (2011) observed that EHV-1 infection of ponies resulted in increased (parallelly to the onset viraemia) expression of mRNA of cytokines important for the development of cytotoxic lymphocytic response (IFN- $\gamma$ ), as well as in increased mRNA expression of regulatory cytokines (IL-10; TGF- $\beta$ ) in peripheral blood mononuclear cells. Also, significant increase in antibody response to EHV-1 on post infection day 14 was recorded. Another finding was that ORF1/2 gene were relevant for disease outcome and modulation of cytokine response. The deletion of ORF1/2 genes from EHV-1 subtype Ab4 attenuates the illness caused by EHV-1 and modulated the IL- 8 and Tbet response (Hussey et al., 2011).

\section{POST VACCINATION IMMUNE RESPONSE TO EQUINE INFLUENZA VIRUS AND EQUINE HERPESVIRUS}

Equine influenza A subtypes, similarly to those affecting other animal species, undergo a constant change and thus, development of new vaccines is often necessitated. Nowadays, different technologies for production of equine vaccines are implemented. In killed vaccines, the agent is completely inactivated by exposure to heat, chemicals or radiation. In many instances, the efficacy of such vaccines requires a strong adjuvant. The inactivated vaccines are efficient but provide a limited protection against the different subtypes and hence, frequent revaccination is mandatory. The new technologies for development of vaccines include gene-based vaccines aimed at enhancing the neutralisation power, scope and duration of protective immunity (Barquero et al., 2007).

In attenuated vaccines, the agent is alive but its pathogenicity is weakened. This type of vaccines produces a more prolonged immunity, but is capable to induce disease in immunocompromised animals (Barquero et al., 2007). Vaccines from this group comprise modified live vaccines attenuated via multiple passages through variants of cell cultures from other species or by production of heatsensitive mutants. In recombinant vector vaccines, DNA of the pathogen is incorporated into another non-pathogenic organism, followed by expression of pathogenic and immunogenic peptide epitopes (Paillot et al., 2006; Barquero et al., 2007).

Ault et al. (2012) described DNA vaccines (expressing a haemagglutinating protein of the equine $\mathrm{H} 3 \mathrm{~N} 8$ influenza $\mathrm{A}$ virus), inducing homologous and heterologous immune response and providing protection against clinical illness and virus propagation via a homologous equine influenza A (H3N8). The authors affirmed that DNA vaccines represented a safe, efficient and reliable alternative for production of veterinary vaccines against equine influenza.

The efficacy of vaccines against equine influenza depends on numerous factors: the time of vaccination, ratio of vaccinal antigens, adjuvant type, and age of horses. It was demonstrated that the duration of maternal antibodies ingested pas- 
sively with colostrum, could interfere with the vaccinal response to influenza in foals (Cullinane et al., 2001).

For detection of influenza and vaccine-induced protection, Morley et al. (1995) utilised detection of specific serum antibodies against equine influenza $\mathrm{A}$ virus through the following diagnostic tests: single radial haemolysis (SRH), haemagglutination inhibition test (HIT) and virus neutralisation test (VNT). They found out that antibody titres measured through SRH and HIT agreed with VNT titres. The involvement of cell-mediated immunity in infections provoked by the virus is weak after application of inactivated vaccines (Hannant et al., 1994).

The vaccination against influenza virus could allow infection with a field influenza viral strain due to the immune "window" which is not properly "closed" by vaccination (Paillot et al., 2013a). Another study of the same research team (Paillot et al., 2013b) in ponies experimentally infected with EIV A/eq/Richmond/1/07 two weeks after the second vaccination (immunity peak) demonstrated that immunisation provided a reliable protection against clinical signs of influenza and reduced viral shedding. Also, the level of post vaccination synthesis of a specific INF $\gamma$ against EIV was shown to be increased in peripheral blood lymphocytes, indicating a stimulated cell-mediated immune response. Most immunised horses maintained significant levels of cross-reactive SRH antibodies for a prolonged period, but assaying could be necessitated to detect subjects, responding poorly to vaccination. Similar investigations with non-vaccinated ponies (Edlund et al., 2005) and ponies vaccinated with recombinant ALVAC vaccine against equine influenza $\mathrm{H} 3 \mathrm{~N} 8$ virus, both groups infected by the $2^{\text {nd }}$ post-vaccination week, showed severe clinical signs of influenza (fever, cough, nasal discharge and dyspnea) in non-vaccinated animals while immunised exhibited serous nasal discharge only for 1 day. The shedding of the virus was almost entirely suppressed in vaccinated ponies whereas non-vaccinated continued to excrete the virus until the $7^{\text {th }}$ day of infection.

Bryant et al. (2010) demonstrated that vaccination with novel ISCOM-based and canarypox-based EIV vaccines could partly protect against infection with $\mathrm{A} / \mathrm{eq} /$ Sydney H3N8/2888-8/07-similar strains and could assist in restricting the spread of the infection in horses. Similar results are reported by Paillot et al. (2010) after application of vaccine Duvaxyn IE-T Plus, which reduces clinical signs and viral shedding in ponies infected with a A/eq2/Sydney/2888-8/07 (H3N8) strain.

Furthermore, clinical signs in nonvaccinated control animals could vary at the time of vaccination in association of strains used for experimental infection (Daly et al., 2011).

Infections with EHV-1 and EHV-4 are controlled through vaccinations with inactivated or modified live viruses (MLV). The successful vaccination requires involvement of humoral and cell-mediated immune response as well. In the view of Slater (2007), a common trait of modern commercial vaccines is that they raise a high titre of virus-neutralising antibodies in adult horses, probably booster antibodies, but induce a weaker or perhaps undetectable response in immunologically naive animals, especially foals. There is little evidence that existing vaccine could stimulate a significant cellular immune response.

Paillot et al. (2008) reported that vaccinal humoral response was most frequently assayed by the complement fixing 
test (CFT) and/or VNT against EHV-1 and EHV-4. Seroconversion is defined by significant increase (4-fold) of antibody titres. Cell-mediated immune response could be assessed by measurement of: antigen-specific $\mathrm{T}$-cell proliferation; the activity of EHV-1 specific CTL, increased expression of mRNA for cytokines or EHV-1 specific synthesis of INF $\gamma$.

Bresgen et al. (2012) compared the efficiency of EHV-1/EHV-4 inactivated combined vaccine and MLV vaccine with regard to the induction of humoral response and protection from clinical disease in 3,500 horses, pregnant mares (abortions) and foals. No statistically significant differences were established between the groups in connection with the magnitude and duration of the humoral response evaluated by serum neutralising antibody titre (1:42 to $1: 130)$ and EHV-1specific IgG isotypes, although the neutralisation response was higher in MLVvaccinated animals throughout the entire study period. Foals born from vaccinated mares exhibited marked decrease of the serum neutralising antibody titre (below $1: 8$ on the average) in all groups, indicating that the half-life of maternal antibodies was less than 4 weeks.

The vaccination with a commercial inactivated combined vaccine against EHV1/EHV-4 did not attenuate the clinical signs or did not influence the viraemia, but reduced the nasal discharge of the virus and apparently, diminished the incidence of abortions. There are no data the vaccine provided protection against nervous signs induced by EHV-1 (Slater, 2007).

After triple application of an inactivated combined vaccine against rhinopneumonitis and influenza to pregnant mares (during the $5^{\text {th }}, 7^{\text {th }}$ and $9^{\text {th }}$ gestational months), Chenchev et al. (2002) detected a stable immune response, ade- quate for protection of the foetus, using two assay methods: VNT and CFT.

To distinguish the vaccinal immune response from the response to EHV-1 infection in horses by the $10^{\text {th }}$ post vaccination month, Goodman et al. (2012) used detection of serum virus-neutralising antibodies, assay of serum IgG isotypes and cytokine profile of lymphocyte subpopulations. The authors established that IgG isotype response to EHV-1 was different under field conditions as compared to experimental setting and that MLV vaccine induced a more limited IgG isotype response than the natural EHV-1exposure. In the group of animals having survived EHV-1 infection and vaccinated afterwards, the authors found out the number of specific INF- $\gamma$ producing CD4+ T lymphocytes (but not that of CD8+) was increased unlike horses which were vaccinated only. Further, INF- $\alpha$ secretion was similar in both studied groups.

The utilisation of monovalent EHV vaccine containing modified attenuated EHV-1 and bivalent EHV vaccine containing inactivated EHV-1 and EHV-4 showed that both induced a considerable increase in serum antibodies measured through ELISA although the level was higher in horses receiving the bivalent inactivated vaccine (Ellis et al., 1995). As the cellular immunity was concerned, no IL-2 activity was observed in a mononuclear leukocyte culture, but interferon activity existed in similar cell cultures in horses immunised with the two types of vaccines. In our preliminary investigations in horses vaccinated with booster dose of oil adjuvant polyvalent inactivated vaccine against influenza and rhinopneumonitis (Fluvac ${ }^{\circledR}$ EHV4/1 Plus, Ford Dodge, Iowa, USA) altered innate immune response along with reduced serum lysozyme concentrations (by the $21^{\text {st }}$ post 
vaccination day) and complement activity (by the $14^{\text {th }}$ and $21^{\text {st }}$ day) were demonstrated. These changes corresponded to increase in anti-EHV-1 and especially in anti-EHV-4 antibody level, as well as increased titres of antibodies against EIVA1 and EIV-A2 compared to pre-vaccination levels (Goundasheva et al., 2002).

The efficacy of vaccination with bivalent EHV1/4 vaccine against respiratory signs was studied by Heldens et al. (2001). Initially, they vaccinated weaned foals twice with the vaccine. Two weeks after the second bout, the foals and a group of untreated foals were intranasally infected with EHV-4. The results from their studies showed a clear reduction of clinical respiratory signs and virus shedding after EHV-4 challenge in vaccinated foals compared to intact ones. Barquero et al. (2007) reported that the inactivated EHV1/4 vaccine reduced the incidence of EHV-1 abortions and the severity and duration of respiratory disease after EHV-1 or EHV-4 infection. Mares and foals vaccinated twice with subunit vaccine containing $\mathrm{gG}$ and $\mathrm{gD}$ glycoproteins from EHV-1 and Iscomatrix ${ }^{\mathrm{TM}}$ adjuvant exhibited lower rate of virus shedding after infection with EHV-1 (Foote et al., 2006). The EHV-1 cell- associated viraemia was however not altered.

The vaccination-generated immunity to EHV-1 and EHV-4 is short (several months), so its maximum efficacy requires several booster doses of a vaccine, recommended by the manufacturer in accordance with the current epidemiological situation in the region and the area of future residence of horses (Allen, 2002; Anonymous, 2008).

In conclusion, all reviewed literature sources made clear than the efficient immune response to antigens of equine influenza $A$ virus and equine herpesvirus 1 and 4 and adequate systemic protection demand a combination of local respiratory tract mucosal immunity, systemic humoral and cell-mediated immune response. The exploration of associated specific mechanisms of defense will require detailed investigations in the future.

\section{REFERENCES}

Allen, G., M. Yeargan, L. R. Costa \& R. Cross, 1995. Major histocompatibility complex class I-restricted cytotoxic T-lymphocyte responses in horses infected with equine herpesvirus 1. Journal of Virology, 69, 606-612.

Allen, G. P., 2002. Respiratory infections by equine herpesvirus types 1 and 4 . In: Equine Respiratory Disease, ed P. Lekeux, International Veterinary Information Service, Ithaca, New York, USA.

Allen, G. P., 2006. Antemortem detection of latent infection with neuropathogenic strains of equine herpesvirus-1 in horses. American Journal of Veterinary Research, 67, 1401-1405.

Anonymous, 2008. OIE Terrestrial Manual. Chapter 2.5.9. Equine rhinopneumonitis. pp. 894-903.

Ault, A., A. M. Zajac, W. P. Kong, J. P. Gorres, M. Royals, C. J. Wei, S. Bao, Z. Y. Yang, S. E. Reedy, T. L. Sturgill, A. E. Page, J. Donofrio-Newman, A. A. Adams, U. B. Balasuriya, D. W. Horohov, T. M. Chambers, G. J. Nabel \& S. S. Rao, 2012. Immunogenicity and clinical protection against equine influenza by DNA vaccination of ponies. Vaccine, 30, 3965-3974.

Barquero, N, J. R. Gilkenson \& J. R. Newton, 2007. Evidence-based immunization in horses. Veterinary Clinics of North America: Equine Practice, 23, 481-508.

Breathnach, C. C, M. R. Yaergan, A. S. Sheoran \& G. P. Allen, 2001. The mucosal humoral immune response of the horse to infective challenge and vaccination with 
equine herpesvirus-1 antigens. Equine Veterinary Journal, 33, 651-657.

Bresgen, C., M. Lämmer, B. Wagner, N. Osterrieder \& A. M. Damiani, 2012. Serological responses and clinical outcome after vaccination of mares and foals with equine herpesvirus type 1 and 4 (EHV-1 and EHV4). Veterinary Microbiology, 160, 9-16.

Bryant, N. A., R. Paillot, A. S. Rash, E. Medcalf, F. Montesso, J. Ross, J. Watson, M. Jeggo, N. S. Lewis, J. R. Newton \& D. M. Elton, 2010. Comparison of two modern vaccines and previous influenza infection against challenge with an equine influenza virus from the Australian 2007 outbreak. Veterinary Research, 41, 19.

Cullinane, A., J. Weld, M. Osborne, M. Nelly, C. McBride \& C. Walsh, 2001 Field studies on equine influenza vaccination regimes in thoroughbred foals and yearlings. The Veterinary Journal, 161, 174-185.

Chenchev, I., G. Georgiev \& S. Yordanov, 2002. Vaccination schedule for the various categories of solipeds in Bulgaria. Veterinarna Sbirka, 2-3, 18-20 (BG).

Daly, J. M., S. MacRae, J. R. Newton, E. Wattrang \& D. M. Elton, 2011. Equine influenza: A review of an unpredictable virus. The Veterinary Journal, 189, 7-14.

Daly, J. M., J. R.Newton Jr \& J. A. Mumford, 2004. Current perspectives on control of equine influenza. Veterinary Research, $\mathbf{3 5}$ 411-423.

Diaz-Mendez, A., L. Viel, J. Hewson, P. Doig, S. Carman, T. Chambers, A. Tiwari \& C. Dewey, 2010. Surveillance of equine respiratory viruses in Ontario. The Canadian Journal of Veterinary Research, 74, 271278.

Edington, N., C. G. Bridges \& J. R. Patel, 1986. Endothelial cell infection and thrombosis in paralysis caused by equid herpesvirus-1: Equine stroke. Archives of Virology, 90, 111-124.

Edlund, T. C., J. Daly, T. Sindle, P. M. Guigal, J. C. Audonnet \& J. M. Minke, 2005. Efficacy of a recombinant equine influenza vaccine against challenge with an Ameri- can lineage H3N8 influenza virus responsible for the 2003 outbreak in the United Kingdom. Veterinary Record, 156, $367-$ 371.

Ellis, J. A., J. R. Bogdan, E. W. Kanara, P. S. Morley \& D. M. Haines, 1995. Cellular and antibody responses to equine herpes 1 and 4 folowing vaccination of horses with modified-live and inactivated viruses. Journal of the American Veterinary Medical Assocciation, 206, 823-832.

Foote, C. E., S. L. Raidel, G. Pecenpetelovska, J. E. Wellington \& J. M. Whalley, 2006. Inoculation of mares and very young foals with EHV-1 glycoproteins D and B reduces virus shedding following respiratory chalenge with EHV-1. Veterinary Immunology and Immunopathology, 111, 97-108.

Goehring, L. S., S. C.van Winden, C. van Maanen \& S. van Oldruitenborgh-Oosterbaan, 2006. Equine herpesvirus type 1assocated myeloencephalopathy in the Netherlands: A four-year retrospective study (1999-2003). Journal of Veterinary Internal Medicine, 20, 601-607.

Goodman, L. B., C. Wimer, E. J. Dubovi, C. Gold \& B. Wagner, 2012. Immunological correlates of vaccination and infection for equine herpesvirus 1. Clinical Vaccine Immunology, 19, 235-241.

Goundasheva, D., L. Sotirov, I. Chenchev, T. Karadjov \& G. Barzev, 2002. Influence of booster vaccination against influenza and equine herpes virus $4 / 1$ on some parameters of the immune response in horses. Revue de Médecine Vétérinaire, 153, 569-574.

Hannant, D., D. M. Jessett \& T. O’Neill, 1994. Cellular immune responses stimulated by inactivated virus vaccines and infection with equine influenza virus (H3N8). In:. Equine Infectious Diseases VII: Proceedings of the Seventh International Conference on Equine Infectious Diseases, eds $\mathrm{H}$. Nakajima \& W. Plowright. Newmarket (UK): R\&W Publications Ltd, pp. 169-174.

Heldens, J. G. M., D. Hannant, A. A. Cullinane, M. J. Prendergast, J. A. Mumford, M. Nelly, J. H. Kydd, M. W. Weststrate \& 
R. van den Hoven, 2001. Clinical and virological evaluation of the efficacy of an inactivated EHV1 and EHV4 whole virus vaccine (Duvaxyn EHV 1,4). Vaccination/challenge experiments in foals and pregnant mares. Vaccine, 19, 4307-4317.

Hussey, G. S., S. B.Hussey, B. Wagner, D. W. Horohov, G. R. Van de Walle, N. Osterrieder, L. S. Goehring, S. Rao \& D. P. Lunn, 2011. Evaluation of immune responses following infection of ponies with an EHV-1 ORF 1/2 deletion mutant. Veterinary Research, 42, p.23. doi: 10.1186/ 1297-9716-42-23.

Kydd, J. H., E. Wattrang \& D. Hannant, 2003. Pre-infection frequencies of equine herpes1 specific, cytotoxic T-lymphocytes correlate with protection against abortion following experimental infection of pregnant mares. Veterinary Immunology and Immunopathology, 96, 207-217.

Kydd, J. H., H. G. Towsend \& D. Hannant, 2006. The equine immune response to equine herpesvirus-1: The virus and its vaccines. Veterinary Immunology and Immunopathology, 111, 15-30.

Landolt, G. A., H. G. Townsend \& D. P. Lunn, 2007. Equine influenza infection. In: Equine Infectious Diseases. ed. D. C. Sellon \& M. T. Long, Saunders, Elsevier, St.Louis, pp. 124-134.

McMichael, A. J., F. M. Gotch, P. Cullen, B. A. Askonas \& R. G. Webster, 1983. Cytotoxic $\mathrm{T}$ cell immunity to influenza. The New England Journal of Medicine, 309, 13-17.

Mohd-Azmi, M. L., J. Gison, F. Rixon, J. McLauchlan \& H. J. Field, 2002. Protection of specific-pathogen-free (Spf) foals from severe equine herpesvirus type-1 (EHV-1) infection following immunization with non-infectious L-particles. The Journal of Microbiology, 40, 183-192.

Morley P. S., L. K. Hanson, J. R. Bogdan, H. G. Townsend, J. A. Appleton \& D. M. Haines, 1995. The relationship between single radial hemolysis, haemaglutination inhibition, and virus neutralization assays used to detect antibodies specific for equine influenza viruses. Veterinary Microbiology, 45, 81-92.

Paillot, R., D. Hannant, J. H. Kydd \& J. M. Daly, 2006. Vaccination against equine influenza: Quid novi? Vaccine, 24, 40474061.

Paillot, R., J. M. Daly, R. Luse, F. Montesso, N. Davia-Poynter, D. Hannant \& J. H. Kydd, 2007. Frequency and phenotype of EHV-1 specific, INF-gamma synthesing lymphocytes in ponies: The effects of age, pregnancy and infection. Developmental \& Comparative Immunology, 31, 202-214.

Paillot, R., R. Case, J. Ross, N. Newton \& R Nugent, 2008. Equine herpes virus-1: Virus, immunity and vaccines. The Open Veterinary Science Journal, 2, 68-91.

Paillot, R., L. Prowse, C. Donald, E. Medcalf, F. Montesso, N. A. Bryant, J. Watson, M. Jeggo, D. M. Elton, J. R. Newton, P. Trail \& H. Barnes, 2010. Efficacy of a whole inactivated EI vaccine against a recent EIV outbreak isolate and comparative detection of virus shedding. Veterinary Immunology and Immunopathology, 136, 272-283.

Paillot, R., L. Prowse, F. Montesso, C. M. Huang, H. Barnes \& J. Escala, 2013a. Whole inactivated equine influenza vaccine: Efficacy against a representative clade 2 equine influenza virus, INFgamma synthesis and duration of humoral immunity. Veterinary Microbiology, 162, 396-407.

Paillot, R., L. Prowse, F. Montesso, B. Stewart, L. Jordon, J. R. Newton \& J. R. Gilkenson, 2013b. Duration of equine influenza virus shedding and infectivity in immunised horses after experimental infection with EHV A/eq2/Richmond/1/07. Veterinary Microbiology, 166, 22-34.

Perkins, G., D. M. Ainsworth, H. N. Erb, F. Del Piero, M. Miller, P. A. Wilkins, J. Palmer \& M. Frazer, 1995. Clinical, haematological and biochemical finding in foals with neonatal Equine herpes-1 infection compared with septic and premature foals. Equine Veterinary Journal, 31, 422-426. 
Powell, D. G., 1991. Viral respiratory disease of the horse. Veterinary Clinics of North Americ: Equine Practice, 7, 27-52.

Pusterla, N., W. D. Wilson, J. E. Madigan \& G. L. Ferraro, 2009. Equine herpesvirus-1 myeloencephalopathy: A review of recent developments. The Veterinary Journal, 180, 279-289.

Slater, J. D., J. S. Gibson \& K. C. Barnett, 1992. Chorioretinopathy associated with neuropathology following infection with equine herpesvirus-1. The Veterinary Record, 131, 237-239.

Slater, J. D., 2007. Equine herpesviruses. In: Equine Infectious Diseases, ed. D. C. Sellon \& M. T. Long. Saunders, Elsevier St. Louis, 134-153.

Tsachev, I., P. Petkov \& M. Deyanov, 1994. Clinical, biochemical and haematological studies on influenza in equids. In: Proceedings from the $5^{\text {th }}$ Conference of Young Researchers "Modern Trends in Fundamental and Applied Sciences", Stara Zagora, pp. 87-90 (BG).

Tsachev, I., 2007. Equine Infectious Diseases. Contrast, Stara Zagora (BG).
Van der Meulen, K. M., H. W. Favoreel, M. B. Pensaert \& H. J. Nauwynck, 2006. Immune escape of equine herpes 1 and other herpesvirus of veterinary importance. Veterinary Immunology and Immunopathology, 111, 31-40.

Walter, J., C. Seeh, K. Fey, U. Bleul \& N. Osterrieder, 2013. Clinical observations and management of a severe equine herpesvirus type 1 outbreak with abortion and encephalomyelitis. Acta Veterinaria Scandinavica, 55, 19-27.

Paper received 02.11.2016; accepted for publication 06.02.2017

\section{Correspondence:}

Dimitrina Gundasheva

Department of General and Clinical Pathology, Faculty of Veterinary Medicine, Student's Campus, Trakia University, 6000 Stara Zagora, Bulgaria e-mail: d_gundasheva@abv.bg 